\title{
Comparison in optoelectronic properties of triphenylamine-imidazole or imidazole as donor for dye-sensitized solar cell: Theoretical approach
}

Assia Bourouina ( $\sim$ bourouinaassia@gmail.com )

Universite des Sciences et de la Technologie Houari Boumediene https://orcid.org/0000-0001-59950252

\section{Mâammar Rekis}

Universite des Sciences et de la Technologie Houari Boumediene

\section{Original paper}

Keywords: DSSC, Light harvesting efficiency, Triphenylamine, D-D-п-A, DFT/TD-DFT

Posted Date: February 10th, 2021

DOl: https://doi.org/10.21203/rs.3.rs-201458/v1

License: (c) (i) This work is licensed under a Creative Commons Attribution 4.0 International License.

Read Full License

Version of Record: A version of this preprint was published at Journal of Molecular Modeling on July 13th, 2021. See the published version at https://doi.org/10.1007/s00894-021-04844-8. 
Comparison in optoelectronic properties of triphenylamine-imidazole or imidazole as donor for dye-sensitized solar cell: Theoretical approach

Assia Bourouina ${ }^{\mathrm{a}, ~ *,}$ Mâammar Rekis ${ }^{\mathrm{a}}$

a, Theoretical chemistry and computational photonics laboratory, Faculty of Chemistry, Houari Boumediene Sciences and Technology University, BP 32 El Alia, 16111 Algiers, Algeria.

*Corresponding author. Tel: 0775943025

Email address: assiabourouina@hotmail.fr

Keywords:

DSSC

Light harvesting efficiency

Triphenylamine

D-D- $\pi-A$

DFT/TD-DFT 


\begin{abstract}
In the present work, the structural and electronic properties of the D-D'- $\pi$-A organic dye with two donors have been calculated theoretically by DFT/TD-DFT method. In order to prove their efficiency as sensitizers, a comparative study was performed with a serie of D- $\pi$-A architecture with one donor. The results of light harvesting efficiency (LHE), open circuit voltage (Voc), free energy injection $\left(\Delta G_{i n j}\right)$, free energy dye regeneration $\Delta G_{r e g}$, excited-state lifetimes for the two series reveal that the D-D'- $\pi$-A dyes are promising for the design of new sensitive dyes in solar cells.
\end{abstract}

\title{
I. Introduction
}

In the last decades, since the works of Grätzel and O'Regan in 1991 [1], dye-sensitized solar cell (DSSC) has been given special interest from experiment and theory researchers. DSSC mainly consist of redox electrolyte, counter electrode, photo-anode, dye sensitizers adsorbed on the $\mathrm{TiO}_{2}$ semiconductor surface. The sensitizers play a vital role for sunlight harvesting and electrons performance. So far there are two classes of dyes, organic and organometallic [2-5]. Organic sensitizers have shown several merits, lower cost, simple synthesizing process [6-8] and flexibility in tailoring molecular structures in order to enhance electronic and optophysical characteristics [9-12].

Dye sensitizers should fulfill several requirements regarding the efficiency. (i) Their optical absorption should cover a wide section of the visible spectrum and extend up to the near IR region. (ii) To ensure effective electron transfer and efficient dye regeneration, LUMO energy levels have to be above the $\mathrm{TiO}_{2}$ semiconductor conduction band $(\mathrm{CB})(-4.0 \mathrm{eV})$ and the HOMO levels below the redox potential of the $\mathrm{I}^{-} / \mathrm{I}^{-}$electrolyte $(-4.8 \mathrm{eV})$ [13-15]. Thus, there is a close link between the electronic structure, HOMO, LUMO, gap energy and the photo-tocurrent conversion efficiency (PCE).

During the photoexcitation, the electron is transferred from the HOMO, which is located on the donor to the LUMO which is on the acceptor moiety [16].

The organic chromophore consists mainly of three components; a donor moiety linked to an acceptor one via a bridge. The role of each component is vital. The modulation by adding one donor or acceptor moieties may result in multipolar models and consequently exert a significant impact on the sensitizer performances. The use of multi-donors has been proven as 
a good strategy for delaying charge recombination and enhancing the open-circuit photovoltage $V_{o c}[17,18]$.

Among all, several models multidonor have been synthesized or designed theoretically, D-D$\pi$-A, (D- $\pi$-A) 3L2, in order to improve the performance and the efficiency of the dye to absorb more energy from solar spectrum [19-22]. The computation tools have contributed a lot in this field in studying the different molecular designs, to deepen in optoelectronic studies of the different molecules in order to be able to present them as effective candidate dyes [23, 24], as well as to propose them to the experimenter to be synthesized it.

The donor may be quinoxaline [21], quinoline [25] phenothiazine, phenoxazine [26, 27], or triphenylamine [28].

Recently S. Sambathkumar et al [29], synthesized and characterized a novel dye serie of D$\mathrm{D}^{\prime}-\pi$-A design, the triphenylamine - imidazole has been used as a donor entity in order to boost the optoelectronic properties and to better absorb the solar spectrum.

In this paper, we have designed two series of dyes, one based on two donors (Triphenylamine -imidazole), the second based on one donor (imidazole), possessing three different acceptor units by following D-D'- $\pi$-A and D- $\pi$-A approach respectively

\section{Methods}

In this work, we have carried out all the calculations using DFT [30, 31] and TD-DFT [32, 33] together with the GAUSSIAN 16 software package [34]. The geometries have been optimized with DFT by Becke's three-parameter hybrid functional combined with the correlation function of Lee, Yang, Parr B3LYP [35] and the base 6-31G (d, p) [36].

In addition, the vibrational frequencies were calculated; all the frequencies are positive, this indicates that the geometries obtained through optimization correspond to the potential energy surface minima.

Then, the excited states have been calculated using TD-DFT all through CAM-B3LYP[37] functional and the 6-31G $(\mathrm{d}, \mathrm{p})$ base in the $\mathrm{N}, \mathrm{N}$-dimethylformamide solvent (DMF).

It is clear that the CAM-B3LYP functional together with the 6-31G $(\mathrm{d}, \mathrm{p})$ basis have been selected as the best overall functional-basis set which reproduces the most the experimental data $[38,39]$.

The calculation results have enabled us to obtain the geometric parameters, the energies of the frontier molecular orbitals (HOMO and LUMO), the absorbance spectral study of the dyes as well as the photovoltaic parameters. 


\section{Results and discussion}

The investigated dyes with D-D'- $\pi$-A and D- $\pi-A$ architectures are schematized in Fig1. The first serie which is synthesized [29] includes two donors triphenylamine- imidazole named (SD1, SD2, TPAB5) and the second serie is hypothetical consists mainly of imidazole as a donor entity named (SD1', SD2', TPAB5').

In order to get insights on the added donor effect on the geometrical and optoelectronic parameters on the first serie, we have studied and analyzed through DFT and TD-DFT the HOMO, LUMO, distribution of (MOs) along the molecule backbone, light harvesting efficiency, energy electron injection, energy regeneration and life excited states. In addition, we have carefully reported the effect of the electron withdrawing group on the optoelectronic and photovoltaic properties.

\section{III.1Optimizations of the ground state of molecules}

The Selected geometrical parameters shown in Fig. 3 and Fig. 4 are listed in Table 1. From Table 1 we show that the bond length for the two dyes series decreases in this direction: d2> $\mathrm{d} 3>\mathrm{d} 1$. The bond length $\mathrm{d} 3$ remains unchanged because this is the distance between the two donor moieties, which doesn't change at the same time away from the acceptor moiety. At the same time, $\mathrm{d} 2$ is very sensitive to the variation of the acceptor group in the sensitizer from the strongest (cyanoacrylic) to the weakest (nitrophenyl acetonitrile) via the medium (rhodanine acetic acid).

At this point the $\phi 1, \phi 2, \phi 3$ represent the dihedral angles respectively between the D- $\pi, \pi-\mathrm{A}$ and D-D' units. Also from the same table, we notice a kind of deviation from the molecular plane of the donor- $\pi$ unit for SD1, however the planarity is maintained between $D-\pi$ for the dyes SD2 and TPAB5. The values of the dihedral angles $\phi 3$ in the dyes SD1, TPAB5 indicate that the donor-donor groups are co-planar in this structure. Idem for SD2. It results in an excellent delocalization of the electrons in these structures. 


\section{III.2 Electronic properties}

The energy of HOMO and LUMO plays a very important role in the charge transfer between the donor and acceptor part, HOMO is the orbital which mainly acts as an electron donor and LUMO is the orbital which acts as an electron acceptor.

It is possible to obtain the required properties for the dyes for maximum DSSC conversion efficiency, while improving their electronic properties via HOMO and LUMO orbitals [4042].

Those orbitals distributions displayed in Fig. 2. The FMO analysis shows that the HOMOs are delocalized over the donor moiety and LUMOs over the acceptor one. This distribution is essential to ensure good charge transfer from the molecule to the semiconductor and to reduce the chance of charge recombination. The HOMO, LUMO energies, and energy gaps for the investigated dyes are summarized in Table 2. From Table 2 it can be seen that the HOMO values are more stable for dyes with the two donors. That is expectable because the HOMO is delocalized over the donor part. We can also notice that the smallest value of HOMO is assigned to SD2 and SD1. No significant change for LUMO values. The energy gap follows this sequence: TPAB5' $^{\prime}>$ TPAB5 $>$ SD1'>SD2'>SD2>SD1.

\section{III.3 UV-Vis spectra and electronic transitions}

The study of the excited states of the two donors-based dyes (SD1, SD2, and TPAB5) and the mono-based dyes (SD1', SD2' and TPAB5') has been carried out with TD-DFT methods for the first twenty excited state.

Furthermore, to take into account the solvent effect, we have considered the $\mathrm{N}, \mathrm{N}$ dimethylformamide (DMF) for solvent phase calculation and polarizable continuum model (CPCM) as method [43]. The results in Table 3 illustrate the theoretical and experimental absorption wavelength maximum $(\mathrm{nm})$, the excitation energy $(\mathrm{eV})$, oscillator strength and percentage transitions. The simulated UV-vis spectra for all compounds are depicted in Fig 5. During the structural modification, the two donors-based dyes (SD1, SD2 and TPAB5) have presented red-shifts at $404 \mathrm{~nm}, 432 \mathrm{~nm}, 380 \mathrm{~nm}$ respectively, further shifts towards blue were observed with mono donor-based dye (SD1', SD2' and TPAB5'). Consequently, we can notice herein that those results revealed that the nature of acceptor unit strongly affects the absorption spectra. The rhodanine acetic acid units giving rise to the largest absorption wavelengths 432nm for SD2, and absorption wavelengths $380 \mathrm{~nm}$ decrease with cyanoacrylic for TPAB5. An outstanding agreement between the theory and the available experimental 
values has been verified for the wavelength absorbance maxima. We can see in Table $\mathbf{3}$, the $\mathrm{HOMO} \rightarrow$ LUMO transition dominates the absorption band of the absorption spectrum, with contribution $>50$ percentage for all the studied dyes.

\section{III.4 Light harvesting efficiency and open circuit voltage}

Efficient sensitizers to be used in DSSCs should have a large light-harvesting efficiency (LHE), which can be expressed briefly as equation (1) [44], light-harvesting efficiency and other photovoltaic parameters have been described in detail in our previous works [45].

$L H E=1-10^{-f}$

Where $f$ is the oscillator strength at maximum wavelength $\lambda$ max.

The open circuit photovoltage $V_{O C}$ in DSSCs can be calculated from the expression [46]:

$V_{o c}=E_{\text {lumo }}-E_{C B}(2)$

The result values of the oscillator strength $f$, the light harvesting efficiency (LHE) and the open circuit voltage $(V o c)$ are saved in Table 3. From this table it is clear that added of second donor moiety lead to significant impact on oscillator strength. The LHE has to be as high as possible to maximize the photocurrent response. The LHE values for two donors based-dyes (SD1, SD2 and TPAB5) are higher than the ones of the mono donor chromophore (SD1', SD2', and TPAB5'). Finally, the calculated Voc follows the same trend as that of LHE. From, it is concluded that the adding up of a second donor in a dye improves its performance.

\section{III.5 Electron injection and dye regeneration}

The charge transfer within the sensitizer takes place in two stages, the electrons injection into the semiconductor conduction band then the regeneration of the dye ground state.

The electrons injection is measured by $\Delta G_{i n j}$ free energy injection and the regeneration of the dye by $\Delta G_{r e g}$ free energy regeneration. The simulated values for $\Delta G_{i n j}, \Delta G_{r e g}$ are collected in Table 4. All $\Delta G_{i n j}, \Delta G_{r e g}$ values are negative, and this shows that both charge injection and dye regeneration energies are spontaneous processes for the designed sensitizers. The six here considered dyes could efficiently inject the charge into the semiconductor since $\Delta G_{i n j}$ absolute values are higher than the minimum requirement $0.2 \mathrm{eV}[47,48]$. 
Among all dye investigated the two donors-based dye present higher $\Delta G_{i n j}$ values. While the smaller ones $(1.37 \mathrm{eV}, 1.52 \mathrm{eV}, 1.32 \mathrm{eV})$ are noted respectively for SD1', SD2', TPAB5'. The introduction of triphenylamine as second donor enhance the $\Delta G_{i n j}$.

Dye regeneration ability is calculated through the formula:

$\Delta G_{r e g}=E_{I^{-} / I_{3}^{-}}-E_{O X}$

Where $E_{I^{-}} / I_{3}^{-}$is the redox potentiel $I^{-} / I_{3}^{-}$in the solvent.

According to the calculated values of $\Delta G_{r e g}$ reported in Table 4, they are all greater than $(0.4$ eV) [43]. That shows that all dyes can be regenerated.

\section{III.6 Excited-state lifetime}

For the DSSCs, dyes with longer excited-state lifetime $(\tau)$ are expected to show better charge transfer efficiency with low possibility of charge recombination. The excited-state lifetime will be calculated as the equation below [49-52].

$\tau=\frac{1.499}{f \times \Delta E^{2}}$

Where $\Delta \mathrm{E}$ is the excitation energy of the different electronic states $\left(\mathrm{cm}^{-1}\right)$ and $f$ the oscillator strength corresponding to the electronic state.

Finally, Table 4 shows excited-state lifetime $(\tau)$ for all molecules that grows between $1.76 \mathrm{~ns}$ and 3.57ns. Excited-state lifetime for investigated dyes decreases in this direction: SD1'> SD2' $>$ TPAB5' $>$ SD1 $>$ SD2 $>$ TPAB5. This indicates that introducing, different acceptors, and second donor affect $\tau(\mathrm{ns})$.

\section{III.7 Dipole moment in ground and excited state}

The dipole moment of the dye molecule in the ground state and in the excited state also tells us about the performance of a DSSC. Intermolecular charge transfer (ICT) in such architectural systems leads to the polarization of the chromophores and the generation of a molecular dipole. The calculated ground state dipole moment $\left(\mu_{g}\right)$ and excited state dipole moment $\left(\mu_{e x}\right)$ values of the compounds are reported in Table 4. The calculated dipole moments in the excited state are greater than the ground state for the investigated D-D-' $\pi$-A and $\mathrm{D}-\pi$-A dyes see Table 4. We also note that the dipole moment based on imidazole- 
triphenylamine (SD1, SD2, TPAB5) is in the segment [9.17 -15.71] D and the one based on imidazole (SD1', SD2', TPAB5') is in the segment [5.69-11.13] D. The observed values reveal that chromophores with two donors (SD1, SD2, TPAB5) have better push-pull ability both in the ground and excited state compared to mono donor ones.

\section{Conclusion}

In present work, we have studied and compared by DFT/TD-DFT the optoelectronic properties of two and mono donor-based dyes in order to demonstrate the value-added of a second donor, and effect of different anchoring groups, to ensure their ability as promising sensitizers in DSSC.

We have carried out a theoretical study on the dyes synthesized namely, SD1, SD2, and TPAB5 which are already reported in the literature. These dyes were used as reference for the second series of $\mathrm{D}-\pi$-A design.

Herein, we have computed the structural and optoelectronic parameters such as dihedral angles, dipole moment in the ground and excited state, HOMO, LUMO and gap energy values, $\Delta G_{i n j}, \Delta G_{r e g}$, excited life time $\tau, \mathrm{V}_{\mathrm{OC}}$.

Moreover, the results of our studies conceal that the three dyes with D-D'- $\pi$-A approach (SD1, SD2, TPAB5) shows small dihedral angles, appropriate HOMO, LUMO and energy gap for the proper functioning of the cell. The mentioned dyes have $\lambda \max$ in the range $390-467 \mathrm{~nm}$ in the near IR. The calculated dipole moment shows that these dyes have better push-pull ability both in the ground and excited state. The photovoltaic parameters of two donors meet the standards for an efficient dye namely LHE, Voc, electron injection and regeneration energy and excited state life time and their values are better than those of the dyes with single donor (SD1', SD2',TPAB5').

Most of the found values are favoring for double-donor dyes. The SD1, SD2, and TPAB5 can be presented as effective sensitizing dyes for a photovoltaic solar cell.

Declarations:

Funding: N/A

Conflicts of interest/Competing interests: No conflict declared

Availability of data and material: Yes

Code availability: Yes

Authors' contributions: Equal contributions 


\section{References}

[1] B. O'Regan and M. Grätzel, "A low-cost, high-efficiency solar cell based on dyesensitized colloidal TiO2 films," Nature, no. 353, pp. 737-740, 1991.

[2] P. Bomben, K. Robson, B. Koivisto and C. Berlinguette, "Cyclometalated ruthenium chromophores for the dye-sensitized solar cell," Chem. Rev., no. 056, p. 1438-1450, 2012.

[3] A. Mishra, M. K. Fischer and P. Bäuerle, "Metal-free organic dyes for dye-sensitized solar cells: from structure: property relationships to design rules," Angew Chem Intl, no. 48, p. 2474-2499., 2009.

[4] S. Mathew, A. Yella, P. Gao, M. Grätzel, M. K. Nazeeruddin, R. Humphry-Baker, B. F. E. Curchod, N. Ashari-Astani, I. Tavernelli and U. Rothlisberger, "Dye-sensitized solar cells with $13 \%$ efficiency achieved through the molecular engineering of porphyrin sensitizers," Nat Chem, vol. 6, pp. 242-247, 2014.

[5] Z. Yao, M. Zhang, H. Wu, L. Yang and P. Wang, "Donor/acceptor indenoperylene dye for highly efficient organic dye-sensitized solar cells," J Am Chem Soc, 2015.

[6] Z. Yao, H. Wu, Y. Li, J. Wang, J. Zhang, M. Zhang et al, "Dithienopicenocarbazole as the kernel module of low-energy-gap organic dyes for efficient conversion of sunlight to electricity," Energy Environ Sci http://dx.doi.org/10.1039/C5EE02822A., 2015.

[7] Z. Yao, M. Zhang, R. Li, L. Yang, Y. Qiao and P. Wang, "A metal-free n-annulated thienocyclopentaperylene dye: power conversion efficiency of $12 \%$ for dye- sensitized solar cells," Angew Chem Int Ed 54(20):5994e8. http://dx.doi.org/10.1002/anie.201501195., 2015.

[8] A. Mishra, M. K. R. Fischer and P. Bäuerle, "Metal-free Organic Dyes for DyeSensitized Solar Cells: From Structure Property Relationships to Design Rules.," Angew. Chem. Int. Ed. 48, pp. 2474-2499, 2009.

[9] Y. Ooyama and Y. Harima, "Y.Ooyama, Y. Harima, Molecular Designs and Syntheses of Organic Dyes for Dye-Sensitized," European Journal of Organic Chemistry,, pp. 2903 2934, 2009.

[10] S. Hwang, J. H. Lee , C. Park , H. Lee, C. Kim, W. Lee, J. Park , K. Kim and N. G. Park, Chem. Commun., 4887., 2007.

[11] L. Teng-Fei, L. Wei and Z. Hong-Xing, "Rational design of metal-free organic D- $\pi$-A dyes in dye-sensitized solar cells: Insight from density functional theory (DFT) and timedependent DFT (TD-DFT)," Organic Electronics 59, pp. 131-139, 2018. 
[12] J. Chen, C. Tsai, S. Wang, Y. Lin, T. Huang, S. Chiu, C. Wu and K. Wong, J. Org. Chem. 76,, p. 8977-8985, 2011.

[13] X. Lu, S. Wei, C. M. L. Wu, S. Li and W. Guo, J. Phys. Chem. C 115 (9), p. 3753-3761, 2011.

[14] R. Soto-Rojo, J. Baldenebro-López and D. Glossman-Mit, Int. J. Photoenergy. doi:10.1155/2016/6479649, 2016.

[15] M. Singh, R. Kurchania, A. Pockett, R. J. Ball, E. N. Koukaras, P. J. Cameron and G. D. Sharma, "Characterization of metal-free D- $(\pi-A) 2$ organic dye and its application as cosensitizer along with N719 dye for efficient dye-sensitized solar cells," Indian J. Phys. 8.

[16] P. Li et al, "A systematic study of phenoxazine-based organic sensitizers for solar cells," Dyes Pigm. 137,, p. 12-23, 2017.

[17] Z. S. Wang and F. Liu, Front. Chem. China 5, pp. 150-161, 2010.

[18] A. Irfan, Comp. Theor. Chem 1159, pp. 1-6, 2019.

[19] S. Namuangruk, R. Fukuda, M. Ehara, J. Meeprasert, T. Khanasa, S. Morada, T. Kaewin, S. Jungsuttiwon, T. Sudyoadsuk and V. Promarak, , "D-D- $\pi-A-T y p e$ organic dyes for dye-sensitized solar cells with a potential for direct electron injection and a high extinction coefficient: synthesis, characterization, and theoretical investigation," J. Phys. Chem. C 116, p. 25653-25663., 2012.

[20] R. Hilal, S. G. Aziz, O. I. Osman and J. L. Bredas, "Time dependent - density functional theory characterization of organic dyes for dye-sensitized solar cells," Mol. Simul. 43, p. 1523-1531, 2017.

[21] H. Jiang, Y. Wu, A. Islam, M. Wu, W. Zhang, C. Shen, H. Zhang, E. Li, H. Tian and W. $\mathrm{H}$. Zhu, "Molecular engineering of quinoxaline-based D-A- $\pi-\mathrm{A}$ organic sensitizers: taking the merits of a large and rigid auxiliary acceptor," ACS Appl. Mater. Interfaces 1020 ACS Appl. Mater. Interfaces 10, p. 13635-13644, 2018.

[22] W. Yang, D. Cao, H. Zhang, X. Yin, X. Liao, J. Huang, G. Wu, L. Li and Y. Hong; Yang, "Dye-sensitized solar cells based on $(\mathrm{D}-\pi-\mathrm{A}) 3 \mathrm{~L} 2$ phenothiazine dyes containing auxiliary donors and flexible linkers with different length of carbon chain," Electrochim. Acta 283, p. 1732-1741, 2018.

[23] W. Li, J. Wang, J. Chen, F. Q. Bai and H. X. Zhang, "Theoretical investigation of triphenylamine based sensitizers with different p-spacers for DSSC," Spectrochim. Acta Mol. Biomol. Spectrosc. 118, 1144e1151, 2014. 
[24] R. K. Chitumalla and J. Jang, "Density functional theory study on ruthenium dyes and dye@TiO2 assemblies for dye sensitized solar cell applications," Sol. Energy 159, $283 e 290 ., 2018$.

[25] S. B. Ko, A. N. Cho, M. J. Kim, C. R. Lee and N. G. Park, "Alkyloxy substituted organic dyes for high voltage dye-sensitized solar cell: effect of alkyloxy chain length on opencircuit voltage," Dyes Pigments 94, 88e98, https://doi.org/10.1016/j.dyepig.2011.1, 2012.

[26] Y. Yang, Z. He, G. Jiang and F. Liu, "The influence on properties with different conjugated direction of phenoxazine and phenothiazine-based chromophores for organic nonlinear optical materials," Dyes Pigments 176, 108219., 2020.

[27] K. Y. Chiu, V. Govindan, L. C. Lin, S. H. Hunag, J. C. Hu, K. M. Lee, H. H. Tsai, S. H. Chang and C. G. Wu, "DPP containing D- $\pi$-A organic dyes toward highly efficient dyesensitized solar cells," Dyes Pigments 125, 27e35., 2016.

[28] L. Y. Xiaoli, L. Dadong, T. Shanshan and J. Ruifa, "A theoretical approach of starshaped molecules with triphenylamine core as sensitizer for their potential application in dye sensitized solar cells," J. Mol. Graph. Mod. 101, 107704, 2020.

[29] S. Sambathkumar, S. Priyadharshini, M. Fleisch, D. W. Bahnemann, G. Gnana Kumar, S. Kumar, S. Senthilarasu and R. Renganathan, "Design and synthesis of imidazoletriphenylamine based organic materials for dye sensitized solar cells," Materials Letters, 2019.

[30] R. G. Parr and W. Yang, Density-Functional Theory of Atoms and Molecules, New York, 1989, pp. 333-352.

[31] W. Koch and M. C. Holthausen, Chemist's Guide to Density Functional Theory, Weinheim: Wiley-VCH, 2000.

[32] R. Bauernschmitt and R. Ahlrichs, Chem. Phys. Lett. 256, pp. 454-464, 1996.

[33] M. E. Casida, C. Jamorski, K. C. Casida and D. R. Salahu, J. Phys. Chem. 108, 1998.

[34] G. W. Trucks, M. J. Frisch, H. B. Schlegel, G. E. Scuseria, M. A. Robb, J. R. Cheeseman, G. Scalmani, V. Barone, G. A. Petersson, H. Nakats, H. Nakatsuji , X. Li, M. Caricato, A. V. Marenich, J. Bloino, B. G. Janesko, R. Gomperts, B. Mennucci, H. P. Hratchian, J. V. Ortiz, A. F. Izmaylov, J. L. Sonnenberg, D. Williams-Young, F. Ding, F. Lipparini, F. Egidi, J. Goings, B. Pen, A. Petrone, T. Henderson, D. Ranasinghe, V. G. Zakrzewski, J. Gao, N. Rega, G. Zheng, W. Liang, M. Hada, M. Ehara, K. Toyota, R. Fukuda, J. Hasegawa, M. Ishida, T. Nakajima, Y. Honda, O. Kitao, H. Nakai, T. Vreven, K. Throssell, J. A. Montgomery, J. E. J. Peralta, F. Ogliaro, M. J. Bearpark, J. J. Heyd, E. N. Brothers, K. N. Kudin, V. N. Staroverov, T. N. Keith, R. Kobayashi, J. Normand, K. Raghavachari, A. P. Rendell, J. C. Burant, S. S. Iyengar, J. Tomasi, M. Cossi, J. M. 
Millam, M. Klene, C. Adamo, R. Cammi, J. W. Ochterski, R. L. Martin, K. Morokuma, O. Farkas, J. B. Foresman and D. J. Fox, Gaussian 16, Revision B.01, Wallingford, CT: Gaussian, Inc., 2016.

[35] A. D. Becke, "Density-functional thermochemistry. III. The role of exact exchange," $J$. Chem. Phys. 98 (7) 5648e5652, 1993.

[36] A. D. Becke, "A new mixing of HartreeeFock and local density-functional theories," $J$. Chem. Phys. 98 (2) 1372e1377, 1993.

[37] T. Yanai, D. P. Tew and N. C. Handy, "A new hybrid exchange correlation functional using the Coulomb-attenuating method (CAM-B3LYP)," Chem. Phys. Lett. 393 (1e3) 51e57, 2004.

[38] R. N. Almogati, S. G. Aziz and R. Hilal, "Effect of substitution on the optoelectronic properties of dyes for DSSC. A DFT approach," J. Theor. Comput. Chem. 16 (02) 1750018., 2017.

[39] H. C. Zhu, C. F. Li, Z. H. Fu, S. S. Wei, X. F. Zhu and J. Zhang, "Increasing the open circuit voltage and adsorption stability of squaraine dye binding onto the $\mathrm{TiO} 2$ anatase (1 0 1) surface via heterocyclic anchoring groups used for DSSC," Appl. Surf. Sci. 455 1095e1105., 2018.

[40] W. Zhang, J. Wu, Y. WeN, W. Wu and L. Wang, Dyes Pigm. 149, pp. 908-914, 2018.

[41] W. Zhang, P. Heng, H. Su, T. Ren, L. Wang and J. Zhang, J. Phys. Chem. C 122, 2018.

[42] Y. Zhang, Y. Li, C. Chen, L. Wang and J. Zhang, Org. Electron. 49, pp. 255-261, 2017.

[43] V. Barone and M. Cossi, J. Phys. Chem. A102, pp. 1995-2001, 1998.

[44] A. Bourouina, M. Rekhis and M. Trari, "DFT/TD-DFT study of ruthenium bipyridylbased dyes with a chalcogen donor $(\mathrm{X}=\mathrm{S}, \mathrm{Se}, \mathrm{Te})$, for application as dye-sensitized solar cells.," Polyhedron 127, pp. 217-224, 2017.

[45] R. Katoh, T. Yoshihara, K. Hara, G. Fujihashi, S. Takano, S. Murata, H. Arakawa and M. Tachiya, J. Phys. Chem. B 108 , p. 4818-4822, 2004.

[46] C. R. Zhang, Z. J. Liu, Y. H. Chen, H. S. Chen, Y. Z. Wu, W. Feng and D. B. Wang, Curr. Appl. Phys. 10, pp. 77-83, 2010.

[47] S. Wei, K. Li, X. Lu, Z. Zhao, Y. Shao, Y. Dang, S. Li and W. Guo, "Theoretical insight into electronic structure and optoelectronic properties of heteroleptic $\mathrm{Cu}$ (I)-based complexes for dye-sensitized solar cells," Mater. Chem. Phys. 173 139e145, 2016. 
[48] F. Zanjanchi and J. Beheshtian, "Natural pigments in dye-sensitized solar cell (DSSC): a DFT-TDDFT study," J. Iran. Chem. Soc. 1e11, 2018.

[49] N. Wazzan and A. Irfan, "Theoretical study of triphenylamine-based organic dyes with mono-, di-, and tri-anchoring groups for dye-sensitized solar cells,," Org. Electron. 63 328e342., 2018.

[50] Y. Xu, M. Li, Y. Fu, T. Lu, Y. Hu and W. Lu, "Theoretical study of high-efficiency organic dyes with the introduction of different auxiliary heterocyclic acceptors based on IQ1 toward dye-sensitized solar cells," J. Mol. Graph. Model. 86 170e178, 2019.

[51] R. C. Hilborn, "Einstein coefficients, cross sections, f values, dipole moments, et all that," Am. J. Phys. 50 (11) 982e986, 1982.

[52] Y. Li, J. Liu, D. Liu, X. Li and Y. Xu, "DA-p-A based organic dyes for efficient DSSCs: a theoretical study on the role of p-spacer," Comput. Mater. Sci. 161 163e176., 2019. 
Figures



Figure 1

Structures of all dye investigated.



Figure 2

Structure of a dye with two donor showing bond distances and torsional angles 


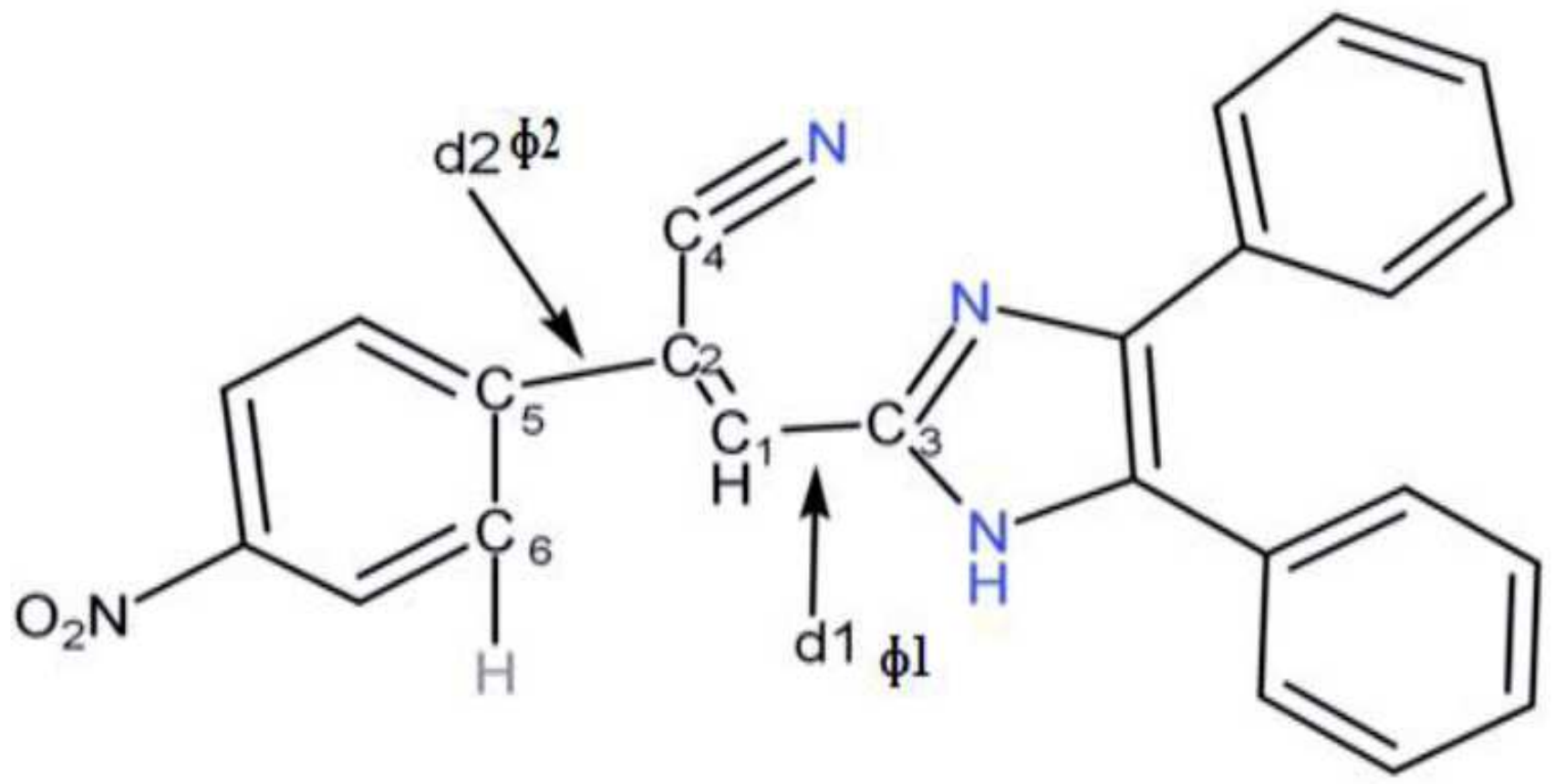

Figure 3

Structure of a dye with one donor showing bond distances and torsional angles
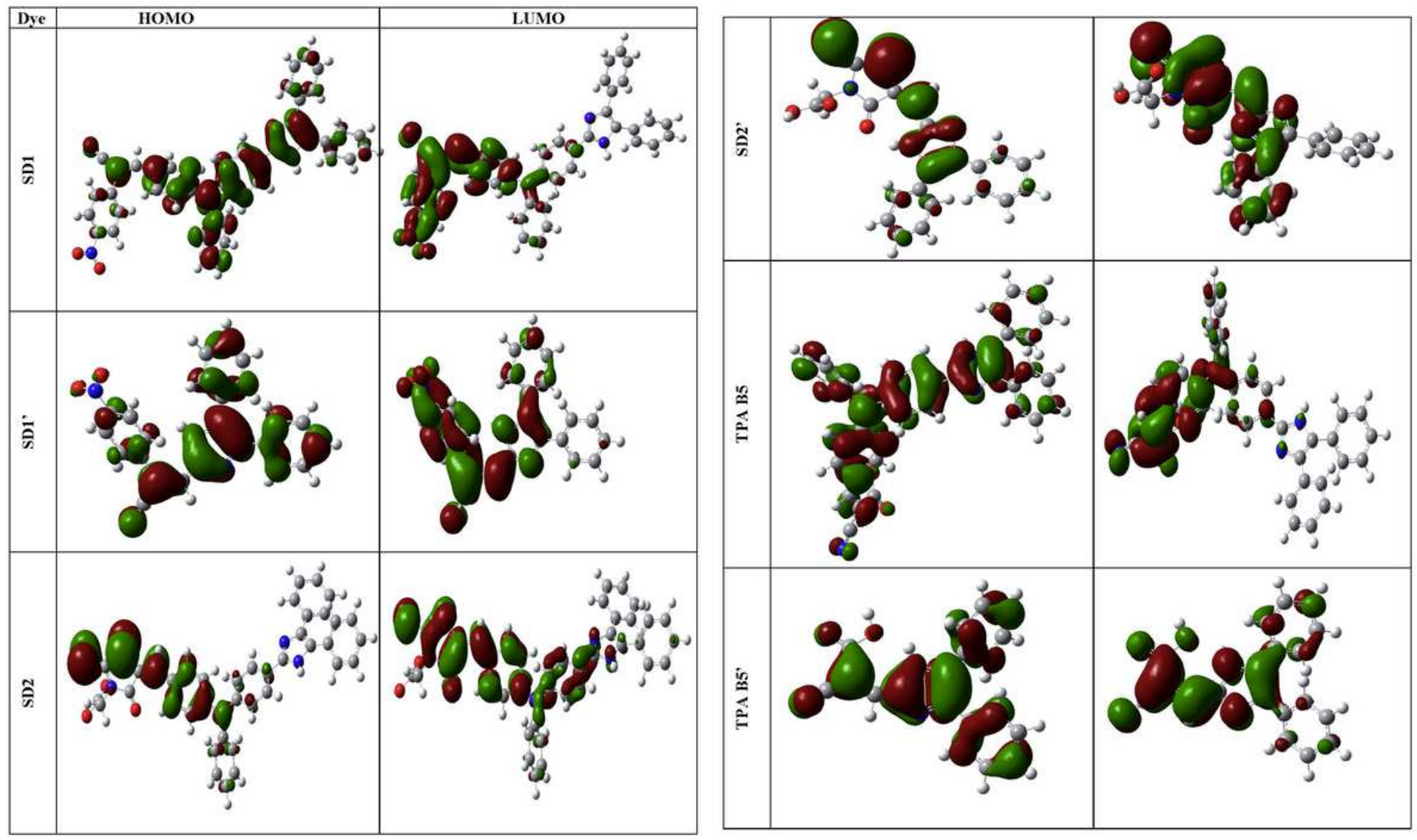

Figure 4 
Distribution both HOMO and LUMO on the backbone of the molecules

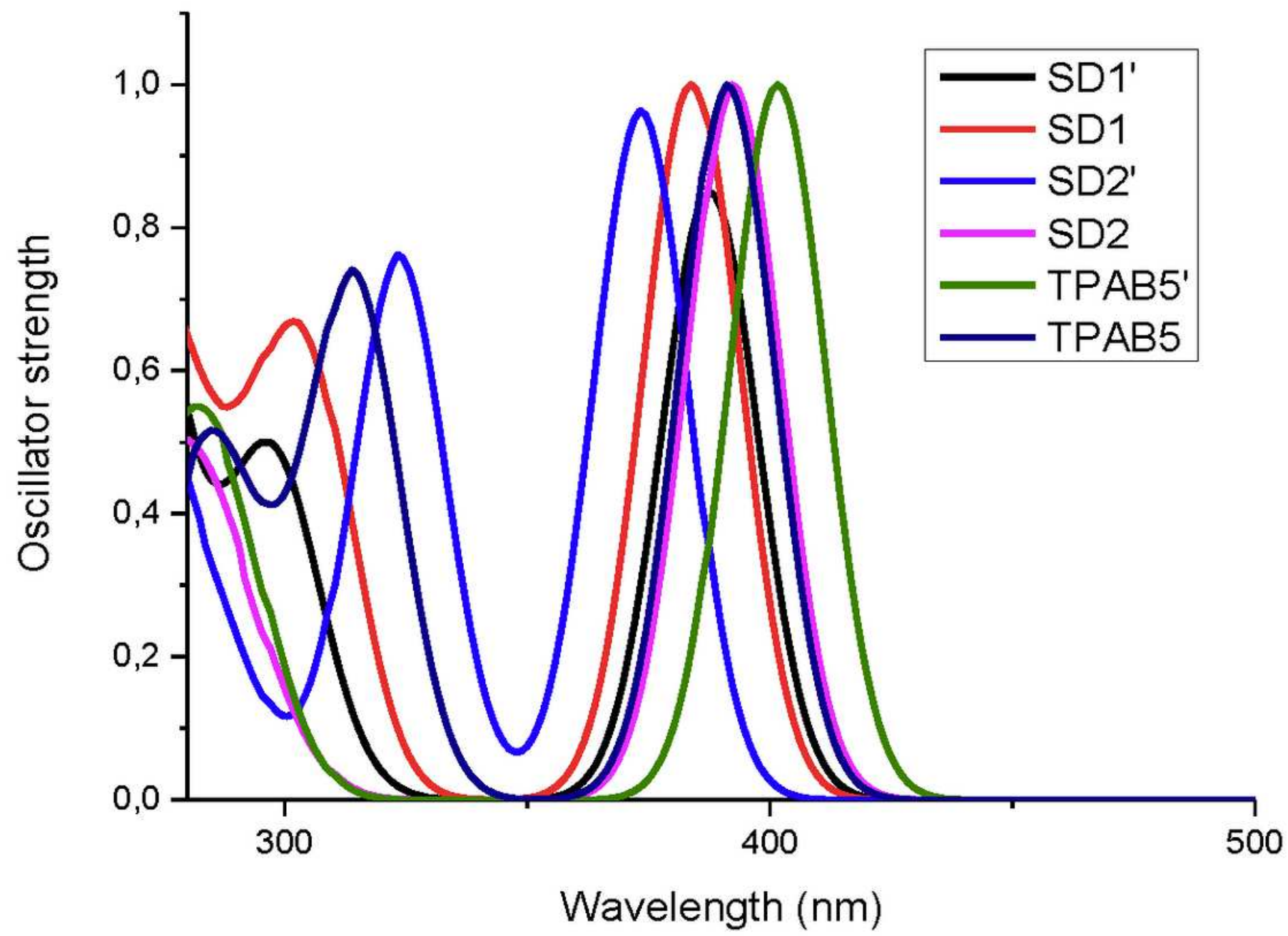

Figure 5

Theoretical Spectra for all dyes calculated at CAM-B3LYP/6-31G (d, P) 